\title{
Delayed hardware complication after lateral retroperitoneal lumbar surgery: an unusual case of painless hematuria
}

\author{
Jeffery R. Head, BA, ${ }^{1,2}$ George N. Rymarczuk, MD, ${ }^{2,3}$ Kevin D. He, BS, ${ }^{1,2}$ and James S. Harrop, MD² \\ ${ }^{1}$ Sidney Kimmel Medical College and 2 Department of Neurosurgery, Thomas Jefferson University, Philadelphia, Pennsylvania; \\ and ${ }^{3}$ Divison of Neurosurgery, Walter Reed National Military Medical Center, Bethesda, Maryland
}

\begin{abstract}
Lateral approaches to the spine are becoming increasingly popular methods for decompression, restoration of alignment, and arthrodesis. Although individual cases of intraoperative injuries to the renal vasculature and the ureters have been documented as rare complications of lateral approaches to the spine, the authors report the first known case of postoperative renal injury due to the delayed extrusion of the screw of a lateral plate/screw construct directly into the renal parenchyma. The migration of the screw from the L1 vertebra into the superior pole of the left kidney occurred nearly 5 years after the index procedure, and presented as painless hematuria. A traditional left-sided retroperitoneal approach had been used at the time of the initial surgery, and the same exposure was used to remove the hardware, which was done in conjunction with general surgery and urology.
\end{abstract}

https://thejns.org/doi/abs/10.3171/2018.5.SPINE171259

KEYWORDS hardware failure; retropulsion; kidney injury; screw; LIF; lumbar interbody fusion

$\mathrm{L}$ ATERAL approaches to the spine are becoming increasingly popular and include traditional retroperitoneal exposures as well as transpsoas approaches. ${ }^{13}$ With recent advances in technology and surgical technique, lateral approaches to the thoracic and lumbar spine can be quickly and safely performed. In many cases, lateral approaches can facilitate more expedient patient recovery while affording surgeons the ability to place a larger interbody graft than is typically possible from more posteriorly directed approaches. ${ }^{3,13}$ Still, a variety of complications unique to these procedures have been reported. . $^{3,15,17}$ Here, the authors describe an unusual case of delayed renal injury presenting as hematuria in a patient who had previously undergone lateral lumbar corpectomy.

\section{Case Report}

A 78-year-old woman developed painless hematuria. Five years previously, the patient had suffered a burst fracture of the L2 vertebra with neurological deficit after a fall from a ladder. At another facility, the patient underwent decompression, stabilization, and fusion via a standard retroperitoneal approach in which lateral L2 corpectomy was performed, followed by insertion of an expandable cage and placement of a lateral plate-and-screw construct extending from $\mathrm{L} 1$ to $\mathrm{L} 3$.

Imaging obtained as part of the workup for new-onset hematuria revealed migration of the lateral screw at L1 into the superior pole of the left kidney (Fig. 1). There was no evidence of hydronephrosis or extravasation of contrast material on enhanced imaging. The patient appeared to have a solid radiographic arthrodesis on dynamic imaging; however, considerable subsidence of the interbody graft was noted. In a combined procedure with neurosurgery, general surgery, and urology, the patient underwent a traditional open-approach lateral retroperitoneal reexposure with removal of the hardware (Fig. 2). The renal parenchyma was coagulated and a drain was left behind to prevent urinoma formation. The drain was removed postoperatively with no urine output noted, and the patient's hematuria resolved completely.

\section{Discussion}

Lateral approaches to the spine, whether retroperitoneal or transpsoas, are an appealing option and are well suited 

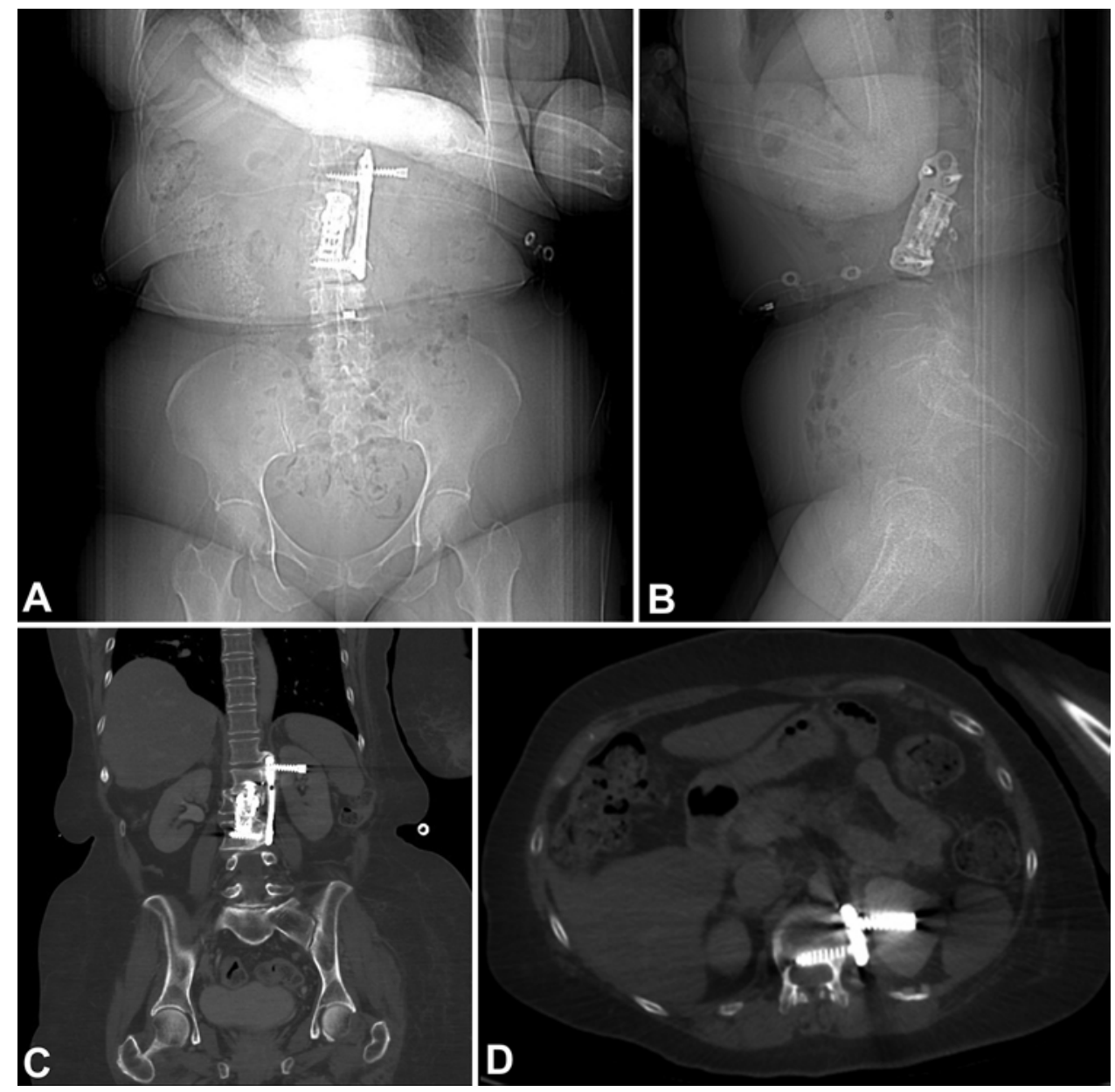

FIG. 1. Preoperative scout CT anteroposterior (A) and lateral (B) views; contrasted CT coronal (C) and axial (D) views demonstrating migration into the renal parenchyma of a screw from a lateral plate-and-screw construct used for lateral lumbar fusion.

to a variety of indications. This approach does, however, carry with it a unique set of challenges and complications. ${ }^{9,15,20}$ The most common complications of both minimally invasive and traditional lateral approaches include pain and sensory changes in the thigh (up to $36 \%$ ), hip flexion weakness, and distal motor weakness due to disruption of the psoas major, as well as traction on the critical neural structures that course therein..$^{6,7,17,23}$ Fortunately, catastrophic injuries such as those to the great vessels and bowel are exceedingly rare. ${ }^{15,20}$

Renal injuries are exceptionally rare. Reports of renal injury following lateral lumbar spine surgery are limited to a handful of instances of ureter disruption, $, 1,10,21,22$ 2 cases of postoperative renal infarction,,$^{1,18} 1$ instance of intraoperative kidney laceration, ${ }^{6}$ and 2 case reports of intraoperative injury to the renal vasculature.,23 This is the first known case of postoperative injury to the kidney parenchyma in the setting of lateral lumbar surgery.

Although many factors contribute to the risk for hardware migration and failure, some of the most relevant variables include appropriate selection of graft size and footprint, choice of graft material, meticulous endplate preparation, and the patient's bone mineral density. Per- haps paramount in this instance, less than ideal graft selection resulted in graft subsidence and ultimately led to the hardware failure that injured the patient's kidney.

Graft size has a considerable impact on graft stability, with devices of larger footprint affording greater contact with cortical bone and more distribution of force, leading to greater biomechanical stability ${ }^{14}$ and lower risk for subsidence. ${ }^{8}$ In addition, correctly sizing the graft, in an effort to avoid over- and underdistraction, can be important with regard to the long-term success of the construct, as was demonstrated in this particular case. Graft material is also an important consideration; polyetheretherketone (PEEK) cages exhibit a decreased modulus of elasticity, closer to that of cancellous bone, compared to grafts of titanium or other similar materials. ${ }^{5}$ PEEK grafts have subsequently been shown to have lower rates of subsidence compared to their metallic counterparts. ${ }^{16}$ Similarly, the quality of the cortical bone present prior to graft implantation contributes to overall stability and decreases the risk of subsidence; improper endplate preparation with excessive removal of cortical bone has been shown to confer greater risk ${ }^{12}$ to the construct. Finally, the patient-specific factor of decreased bone mineral density as indicated by 

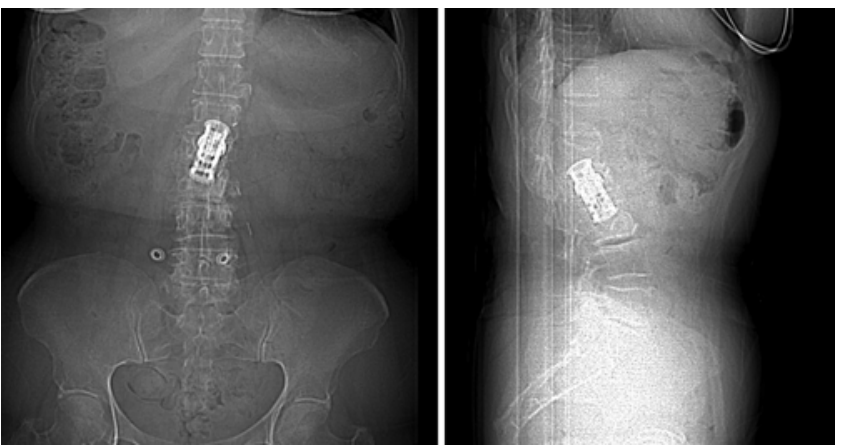

FIG. 2. Postoperative anteroposterior CT view (left) and sagittal CT view (right) demonstrating hardware removal.

lower DEXA T-scores has also been shown to contribute to higher rates of hardware subsidence in both posterior lumbar interbody fusion ${ }^{11}$ and lateral lumbar interbody fu$\operatorname{sion}^{19}$ procedures. Although this is an important preoperative consideration in the patient with spinal deformity who is undergoing elective surgery, one may not have the luxury of addressing baseline osteopenia in the context of trauma or other acute neurological decline.

In the case presented herein, multiple factors probably contributed to the ultimate hardware failure. It appears that a graft that was relatively oversized in craniocaudal dimensions, coupled with perhaps too small of a footprint, was used at the time of the index procedure. The considerable degree of subsidence that ensued ultimately led to the delayed hardware complication. More recently, awareness of spinopelvic harmony is becoming increasingly applied in the context of trauma, and in this instance the relative sagittal plane deformity (Fig. 2) is almost certainly an additional contributing factor to the delayed complication. Diligence regarding these factors in the preoperative planning phase can mitigate such occurrences.

\section{Conclusions}

Renal injury due to delayed hardware failure is a previously unreported complication of lateral lumbar surgery, and requires a high index of suspicion to identify. The risk of long-term sequelae such as this can be avoided with careful planning preoperatively, to include meticulous graft selection among the myriad options that exist, and careful attention to local and global spinopelvic alignment parameters. ${ }^{4}$

\section{Acknowledgments}

Funding was provided by the Department of Neurosurgery, Thomas Jefferson University, Philadelphia, PA.

\section{References}

1. Anand N, Baron EM: Urological injury as a complication of the transpsoas approach for discectomy and interbody fusion. J Neurosurg Spine 18:18-23, 2013

2. Blizzard DJ, Gallizzi MA, Isaacs RE, Brown CR: Renal artery injury during lateral transpsoas interbody fusion: case report. J Neurosurg Spine 25:464-466, 2016
3. Graham RB, Wong AP, Liu JC: Minimally invasive lateral transpsoas approach to the lumbar spine: pitfalls and complication avoidance. Neurosurg Clin N Am 25:219-231, 2014

4. Harrop JS, Rymarczuk GN, Vaccaro AR, Steinmetz MP, Tetreault LA, Fehlings MG: Controversies in spinal trauma and evolution of care. Neurosurgery 80 (3 Suppl):S23-S32, 2017

5. Heary RF, Parvathreddy N, Sampath S, Agarwal N: Elastic modulus in the selection of interbody implants. J Spine Surg 3:163-167, 2017

6. Isaacs RE, Hyde J, Goodrich JA, Rodgers WB, Phillips FM: A prospective, nonrandomized, multicenter evaluation of extreme lateral interbody fusion for the treatment of adult degenerative scoliosis: perioperative outcomes and complications. Spine (Phila Pa 1976) 35 (26 Suppl):S322S330, 2010

7. Kotwal S, Kawaguchi S, Lebl D, Hughes A, Huang R, Sama A, et al: Minimally invasive lateral lumbar interbody fusion: clinical and radiographic outcome at a minimum 2-year follow-up. J Spinal Disord Tech 28:119-125, 2015

8. Lang G, Navarro-Ramirez R, Gandevia L, Hussain I, Nakhla J, Zubkov M, et al: Elimination of subsidence with 26-mmwide cages in extreme lateral interbody fusion. World Neurosurg 104:644-652, 2017

9. Lehmen JA, Gerber EJ: MIS lateral spine surgery: a systematic literature review of complications, outcomes, and economics. Eur Spine J 24 (Suppl 3):287-313, 2015

10. Li JXJ, Phan K, Mobbs R: Oblique lumbar interbody fusion: technical aspects, operative outcomes, and complications. World Neurosurg 98:113-123, 2017

11. Oh KW, Lee JH, Lee JH, Lee DY, Shim HJ: The correlation between cage subsidence, bone mineral density, and clinical results in posterior lumbar interbody fusion. Clin Spine Surg 30:E683-E689, 2017

12. Oxland TR, Grant JP, Dvorak MF, Fisher CG: Effects of endplate removal on the structural properties of the lower lumbar vertebral bodies. Spine (Phila Pa 1976) 28:771-777, 2003

13. Ozgur BM, Aryan HE, Pimenta L, Taylor WR: Extreme Lateral Interbody Fusion (XLIF): a novel surgical technique for anterior lumbar interbody fusion. Spine J 6:435-443, 2006

14. Pimenta L, Turner AWL, Dooley ZA, Parikh RD, Peterson MD: Biomechanics of lateral interbody spacers: going wider for going stiffer. Sci World J 2012:381814, 2012

15. Rodgers WB, Gerber EJ, Patterson J: Intraoperative and early postoperative complications in extreme lateral interbody fusion: an analysis of 600 cases. Spine (Phila Pa 1976) 36:26-32, 2011

16. Seaman S, Kerezoudis P, Bydon M, Torner JC, Hitchon PW: Titanium vs. polyetheretherketone (PEEK) interbody fusion: meta-analysis and review of the literature. J Clin Neurosci 44:23-29, 2017

17. Sofianos DA, Briseño MR, Abrams J, Patel AA: Complications of the lateral transpsoas approach for lumbar interbody arthrodesis: a case series and literature review. Clin Orthop Relat Res 470:1621-1632, 2012

18. Suratwala SJ, Cronin M, Kondra K, Leone V: Acute renal infarction after lateral lumbar interbody spinal fusion for kyphoscoliosis. Spine Deform 4:385-389, 2016

19. Tempel ZJ, Gandhoke GS, Okonkwo DO, Kanter AS: Impaired bone mineral density as a predictor of graft subsidence following minimally invasive transpsoas lateral lumbar interbody fusion. Eur Spine J 24 (Suppl 3):414-419, 2015

20. Uribe JS, Deukmedjian AR: Visceral, vascular, and wound complications following over 13,000 lateral interbody fusions: a survey study and literature review. Eur Spine J 24 (Suppl 3):386-396, 2015 
21. Voin V, Kirkpatrick C, Alonso F, Rustagi T, Sanders FH, Drazin D, et al: Lateral transpsoas approach to the lumbar spine and relationship of the ureter: anatomic study with application to minimizing complications. World Neurosurg 104:674-678, 2017

22. Woods KRM, Billys JB, Hynes RA: Technical description of oblique lateral interbody fusion at L1-L5 (OLIF25) and at L5-S1 (OLIF51) and evaluation of complication and fusion rates. Spine J 17:545-553, 2017

23. Yuan PS, Rowshan K, Verma RB, Miller LE, Block JE: Minimally invasive lateral lumbar interbody fusion with direct psoas visualization. J Orthop Surg Res 9:20, 2014

\section{Disclosures}

The authors report no conflict of interest concerning the materials or methods used in this study or the findings specified in this paper.

\section{Author Contributions}

Conception and design: Head, Rymarczuk. Acquisition of data: Head. Analysis and interpretation of data: Head, Rymarczuk. Drafting the article: Head, Rymarczuk. Critically revising the article: Rymarczuk, He, Harrop. Reviewed submitted version of manuscript: Harrop. Study supervision: Rymarczuk, Harrop.

\section{Correspondence}

Jeffery R. Head: Thomas Jefferson University, Philadelphia, PA. jeffery.head@jefferson.edu. 